\title{
Correction to: Outcomes of Long Pouch Gastric Bypass (LPGB): 4-Year Experience in Primary and Revision Cases
}

\author{
Rui Ribeiro ${ }^{1} \cdot$ Sjaak Pouwels ${ }^{2}$. Chetan Parmar ${ }^{3}$ - João Pereira ${ }^{4} \cdot$ Leonor Manaças ${ }^{4}$ - Anabela Guerra ${ }^{4}$. Nuno Borges ${ }^{4}$. \\ João Ribeiro ${ }^{1} \cdot$ Octávio Viveiros $^{4}$
}

Published online: 17 July 2019

(C) Springer Science+Business Media, LLC, part of Springer Nature 2019

\section{Correction to: Obesity Surgery \\ https://doi.org/10.1007/s11695-019-04051-8}

References $37-44$ are not cited in the article and should be deleted.

Publisher's Note Springer Nature remains neutral with regard to jurisdictional claims in published maps and institutional affiliations.

The online version of the original article can be found at https://doi.org/ 10.1007/s11695-019-04051-8

Sjaak Pouwels

Sjaakpwls@gmail.com

1 Clínica de Santo António, Metabolic Patient Multidisciplinary Centre, Reboleira, Lisbon, Portugal

2 Department of Surgery, Haaglanden Medical Center, Lijnbaan 32, P.O. Box 432, 2501 CK The Hague, The Netherlands

3 Whittington Hospital, London, UK

4 Obesity and Endocrine Diseases Unit, Department of Surgery, Centro Hospitalar de Lisboa Central, Lisbon, Portugal 